\title{
Colorectal cancer treatment in octogenarians: elective or emergency surgery?
}

\author{
Guo Ming-gao ${ }^{*}$, Di Jian-zhong, Wang Yu, Fan You-ben and Huang Xin-Yu
}

\begin{abstract}
Background: The purpose of this research was to assess the characteristics of octogenarian patients with colorectal cancer and compare specific outcomes due to different types of surgical procedures used to treat the disease.

Methods: A total of 346 octogenarian patients undergoing surgery for colorectal cancer between April 2000 and April 2010 were retrospectively assessed according to elective $(n=261)$ or emergent $(n=85)$ admission group. The two groups were compared for clinical variables, surgical procedures, morbidity and mortality, ICU admission, length of hospital stay and overall survival.

Results: The two groups had similar comorbidities. The emergent group had a more advanced Dukes' stage, higher American Society of Anesthesiologists grading, lower anastomosis rate (40.2 vs $80.1 \%$ ), higher stoma rate (30.6 vs $9.6 \%$ ), more complications (71.8 vs $43.3 \%$ ), nine days longer length of hospital stay and higher ( $82.4 \%$ vs $36.4 \%$ ICU admission rate. Overall mortality was 9.5\%, with a higher mortality rate in the emergent group (30.6\%) than the elective group (3.1\%).
\end{abstract}

Conclusions: Octogenarians who undergo elective colorectal cancer surgery have better results than those requiring emergent surgery, but both are quite acceptable and we recommend surgical intervention should not be delayed.

Keywords: Octogenarians, Colorectal cancer, Surgery, Stents, Outcome

\section{Background}

Today, the population is getting older worldwide, with an ever-increasing number of people developing cancer. In this elderly group, colorectal cancer (CRC) is a predominant disease, and about half of all cases occur in patients over 70-years-old. Furthermore, CRC is the second most common cause of cancer death [1].

Treatment of CRC is surgical resection of the primary tumor whenever possible, either for cure or palliation, to avoid late complications, such as obstruction and perforation. Elderly patients may be at risk for later stage and emergent presentation because of insufficient screening, unrecognized symptoms, not deciding whether to receive surgery and inadequate overall access to the healthcare system. Clinical condition is poorer in octogenarian patients with more concomitant illnesses and poorer physiological reserves. Few publications that there are that have reported on outcomes of surgical care of CRC in

\footnotetext{
* Correspondence: guominggao203@hotmail.com

Department of Surgery, The Shanghai Sixth People's Hospital, Shanghai Jiaotong University, Yishan Road 600, 200233 Shanghai, China
}

octogenarian patients have had confused conclusions, and clearly defined guidelines for treatment are lacking $[2,3]$. It is difficult for surgeons to decide whether and which surgery is justified in these patients with a limited life expectancy.

Therefore, the purpose of this study was to assess the characteristics in octogenarian patients with CRC. Additionally, we wished to compare specific outcomes due to different types of surgical procedure used to treat $\mathrm{CRC}$ in this complex patient group, following elective or emergency surgery.

\section{Patients and Methods}

We studied retrospective data of consecutive elderly patients aged 80 years or over, who were diagnosed with CRC and were admitted to the General Surgery Department of the Shanghai Sixth People's Hospital between April 2000 and April 2010. A total of 346 patients were included in this study and all received surgical intervention for CRC. The intention of surgery in all cases was curative resection if at all possible. We excluded patients 
who had endoscopic treatment only. Of these 346 cases, 261 with non-urgent presentations, such as abdominal pain, blood in stool, anaemia, change in bowel habit, mass and weight loss received elective operation and were classed as the elective group. Other 75 patients with acute colonic obstruction and 10 patients with perforation who were classed as the emergent group. Of the patients who presented with acute colonic obstruction, an emergent operation was performed in $64(85.3 \%)$ patients and 11 (14.7\%) received self-expanding metal stents (SEMS) as a bridge to surgery. SEMS' were placed as described previously [4]. All patients' diagnosis of colorectal adenocarcinoma were histologically proven.

Data regarding the patient's clinical features, comorbidities, presentation, method of diagnosis, American Society of Anesthesiologists (ASA) grading, location of tumor, type of treatment, Dukes' staging, treatment outcomes including major 30-day morbidity and mortality, information concerning ICU admission, length of hospital stay and overall survival were collected.

We classified perioperative complications as surgical (bleeding, surgical site infection, anastomotic leak, wound dehiscence and bowel obstruction) or medical (myocardial infarction, deep vein thrombosis, pulmonary embolism, pneumonia, cerebrovascular accident, urinary tract infection, renal failure, multiorgan failure and suffocation). Mortality was defined as that occurring within 30 days postoperatively or before discharge if the patients stayed in the hospital was more than 30 days. Survival was calculated from the time of surgery and survival data were maintained with regular follow-up contact.

All treatment interventions applied in this study including SEMS are officially approved, and are routine therapeutic options for old patients in China. Accordingly, prior to the initiation of the treatments, this work was approved by ethics committee at Shanghai Jiaotong University Affiliated The Six People's Hospital.

\section{Results}

A total of 346 patients were included in this study. Patient characteristics are shown in Table 1. The median age was 83.5 (range: 80 to 92 ) years in elective group and 84.7 (range: 80 to 95) years in emergent group. Comorbidities were similar. A significant difference was found in disease presentation, method of diagnosis and ASA grading. Most patients (83.5\%) in elective group and $100 \%$ patients in emergent group presented with symptoms that prompted a diagnostic evaluation. Of the 261 patients who received elective surgery, $87.4 \%, 12.6 \%$ and $8.8 \%$ were diagnosed by colonoscopy, screening colonoscopy and computerized tomography scan, respectively. These conditions were seen in $43.5 \%, 0.0 \%$ and $100.0 \%$ of in patients undergoing emergent procedures, respectively. Only 33 (9.5\%) patients who did not have
Table 1 Characteristics of two groups of octogenarian patients

\begin{tabular}{|c|c|c|c|}
\hline Variables & $\begin{array}{l}\text { Elective, } \mathrm{n}(\%) \\
\mathrm{N}=\mathbf{2 6 1}\end{array}$ & $\begin{array}{l}\text { Emergent, } n(\%) \\
\mathrm{N}=85\end{array}$ & $P$ value \\
\hline Age, median (range) years & $83.5(80-94)$ & $84.7(80-95)$ & \\
\hline \multicolumn{4}{|l|}{ Gender } \\
\hline Male sex & $117(44.8)$ & $36(42.4)$ & 0.69 \\
\hline \multicolumn{4}{|l|}{ Comorbidities } \\
\hline Hypertension & $54(20.7)$ & $23(27.1)$ & 0.22 \\
\hline COPD & 29(11.1) & $13(15.3)$ & 0.03 \\
\hline Chronic heart disease & $36(13.8)$ & $17(20.0)$ & 0.17 \\
\hline Cerebrovascular disease & $11(4.2)$ & $7(8.2)$ & 0.24 \\
\hline Chronic renal failure & $8(3.1)$ & $2(2.4)$ & 1.00 \\
\hline Diabetes mellitus & $31(11.9)$ & $10(11.8)$ & 0.98 \\
\hline \multicolumn{4}{|l|}{ Clinical presentation } \\
\hline Asymptomatic & $43(16.5)$ & $0(0.0)$ & $<0.01$ \\
\hline Symptomatic & 218(83.5) & $85(100.0)$ & \\
\hline \multicolumn{4}{|l|}{ Diagnostic examination } \\
\hline Colonoscopy & $228(87.4)$ & $37(43.5)$ & $<0.01$ \\
\hline Screening colonoscopy & $33(12.6)$ & $0(0.0)$ & $<0.01$ \\
\hline $\begin{array}{l}\text { Computerized tomography } \\
\text { scan }\end{array}$ & $23(8.8)$ & $85(100.0)$ & $<0.01$ \\
\hline \multicolumn{4}{|l|}{ ASA grading } \\
\hline | - || & 149(57.1) & $35(41.2)$ & $<0.01$ \\
\hline III & 102(39.1) & $23(27.1)$ & \\
\hline IV & 10(3.8) & $24(28.2)$ & \\
\hline V & $0(0.0)$ & $3(3.5)$ & \\
\hline
\end{tabular}

any symptoms were diagnosed by screening colonoscopy in both groups. A higher number of high-risk patients (28.2\% of ASA stage IV and 3.5\% of ASA stage V) were found in emergent group.

Surgical observations are shown in Table 2. A higher number of resection and primary anastomosis (RPA) ( $80.1 \%$ vs $40.2 \%)$, and lower number of resection and stoma (RS) (9.6\% vs 30.6\%) were performed in elective group. The rate of palliative surgery was similar in the two groups. The data show that patients in emergent group presented with advanced Dukes' stage tumors compared to the emergent group (50.6\% C and $24.7 \% \mathrm{D}$ stage versus $30.3 \% \mathrm{C}$ and $16.9 \% \mathrm{D}$ stage).

The overall complication rate was significantly higher in the emergent group (71.8\% vs $43.3 \%)$ (Table 3). Medical complications were more frequent in patients who received emergent surgery $(67.0 \%$ vs $41.8 \%)$ and lower surgical complications were found in the elective group $(7.7 \%$ vs $15.3 \%)$. Emergency was also associated with an increased length of hospital stay and higher rate of admission to ICU. Patients undergoing emergent procedures stayed, on average, nine more days in hospital 
Table 2 Surgical observations, procedures and tumor characteristics

\begin{tabular}{|c|c|c|c|}
\hline Variables & $\begin{array}{l}\text { Elective, } n(\%) \\
N=261\end{array}$ & $\begin{array}{l}\text { Emergent, } \mathrm{n}(\%) \\
\mathrm{N}=85\end{array}$ & $P$ value \\
\hline \multicolumn{4}{|l|}{ Tumor location } \\
\hline Right & $98(37.5)$ & 33(38.8) & 0.83 \\
\hline Left and rectum & $163(62.5)$ & $52(61.2)$ & \\
\hline \multicolumn{4}{|l|}{ Treatment } \\
\hline Curative intent & 234(89.7) & $61(71.8)$ & $<0.01$ \\
\hline Resection + anastomosis & 209(80.1) & $35(41.2)$ & $<0.01$ \\
\hline Resection + ostomy & 25(9.6) & $26(30.6)$ & \\
\hline Palliative intent & $27(10.3)$ & 13(15.3) & 0.22 \\
\hline Stoma & $17(6.5)$ & 10(11.8) & 0.60 \\
\hline Bypass & 10(3.8) & $3(3.5)$ & \\
\hline SEMS & & $11(12.9)$ & \\
\hline \multicolumn{4}{|l|}{ Dukes' staging } \\
\hline Dukes' A and Dukes B & 138(52.9) & $21(24.7)$ & $<0.01$ \\
\hline Dukes' C & $79(30.3)$ & 43(50.6) & \\
\hline Dukes' D & $44(16.9)$ & $21(24.7)$ & \\
\hline
\end{tabular}

and $82.4 \%$ of patients required ICU admission. The overall mortality was $9.5 \%$, with an obviously higher mortality in emergent group (30.6\%) than elective group (3.1\%).

Acute bowel obstruction was the major complication of $\mathrm{CRC}$ in octogenarian patients. In emergent group, 75 (88.2\%) patients presented with acute colonic obstruction and 11 received SEMS. Table 4 shows the outcomes of SEMS compared to emergent surgery. A lower rate of overall complication (76.6\% vs $36.4 \%)$ and medical complication (68.8\% vs $27.3 \%$ ) was found. The rate of stoma creation was higher in patients in the emergent group $(50.0 \%$ vs $9.1 \%)$. It appears that mortality was

Table 3 Comparison of outcomes between elective and emergent surgical procedures

\begin{tabular}{lllc}
\hline Outcome & $\begin{array}{l}\text { Elective, } \mathbf{n}(\%) \\
\mathbf{N}=\mathbf{2 6 1}\end{array}$ & $\begin{array}{l}\text { Emergent, } \mathbf{N}(\%) \\
\mathbf{N}=\mathbf{8 5}\end{array}$ & $\boldsymbol{P}$ value \\
\hline Complications & & & $<0.01$ \\
Overall & $113(43.3)$ & $61(71.8)$ & $<0.01$ \\
Medical & $109(41.8)$ & $57(67.0)$ & 0.04 \\
Surgical & $20(7.7)$ & $13(15.3)$ & $<0.01$ \\
ICU admission & $95(36.4)$ & $70(82.4)$ & $<0.01$ \\
Length of stay (days), & $12(4-55)$ & $21(1-92)$ & $<0.01$ \\
median (range) & & & $<0.01$ \\
Mortality & $8(3.1)$ & $26(30.6)$ & $<0.01$ \\
1-year survival & $197(75.5)$ & $37(43.5)$ & $11(12.9)$ \\
3-year survival & $121(46.4)$ & & \\
\hline
\end{tabular}

Table 4 Comparison of outcomes between emergent surgical procedures and self-expanding metal stents

\begin{tabular}{|c|c|c|c|}
\hline Outcome & $\begin{array}{l}\text { Emergent surgery, } \\
\mathrm{n}(\%) \mathrm{N}=64\end{array}$ & $\begin{array}{l}\text { SEMS, } n(\%) \\
\mathrm{N}=11\end{array}$ & $P$ value \\
\hline \multicolumn{4}{|l|}{ Complications } \\
\hline Overall & 49(76.6) & $4(36.4)$ & 0.02 \\
\hline Medical & $44(68.8)$ & $3(27.3)$ & 0.02 \\
\hline Surgical & $8(12.5)$ & $2(18.2)$ & 0.95 \\
\hline Rate of stoma & $32(50.0)$ & $1(9.1)$ & 0.03 \\
\hline ICU admission & 49(76.6) & $5(45.5)$ & 0.10 \\
\hline $\begin{array}{l}\text { Length of stay (days), } \\
\text { median (range) }\end{array}$ & $21(1-92)$ & $24(8-40)$ & \\
\hline Mortality & 20(31.3) & $1(9.1)$ & 0.25 \\
\hline 1-year survival & 28(43.8) & $5(60.0)$ & 1.00 \\
\hline 3-year survival & $7(10.9)$ & $1(10.0)$ & 1.00 \\
\hline
\end{tabular}

lower in patients who received SEMS treatment (31.3\% vs $9.1 \%$ ), but this data were not significant.

Patients were followed up for an average of 36.0 months (range: 2.0 to 60.0 months). The overall median survival was 25.6 months. When overall survival was analyzed by type of procedure, patients in elective group had a median survival of 31.7 months, a one-year survival rate of $75.5 \%$ and a three-year survival rate of $46.4 \%$. In comparison, patients in the emergent group had a dramatic decrease in overall median survival of 10.8 months, a one-year survival rate of $43.5 \%$ and a three-year survival rate of $12.9 \%$. Patients received SEMS had a similar overall median (11.5 months) and survival rate $90.9 \%$ as emergent group (Figure 1).

\section{Discussion}

Colorectal cancer is a predominantly a disease of elderly people and is a major cause of mortality in the elderly population [2]. Historically, it was suggested that octogenarian patients do not fare well after surgery for CRC, with high rates of emergency presentations, higher postoperative morbidity and mortality. Analysis of several recently published reports shows that elective CRC resection in the elderly population is worthwhile and should be carried out for the same indications as for younger patients $[5,6]$. The present study is to assess the characteristics of and compare specific outcomes of elective or emergent surgery in this complex octogenarians group.

As the human body gets old, cumulative physiologic stressors lead to overall decline in organ and tissue function. Physiologic reserves are significantly diminished in octogenarians, and cardiovascular, pulmonary and endocrine comorbidities are common. In a study of 


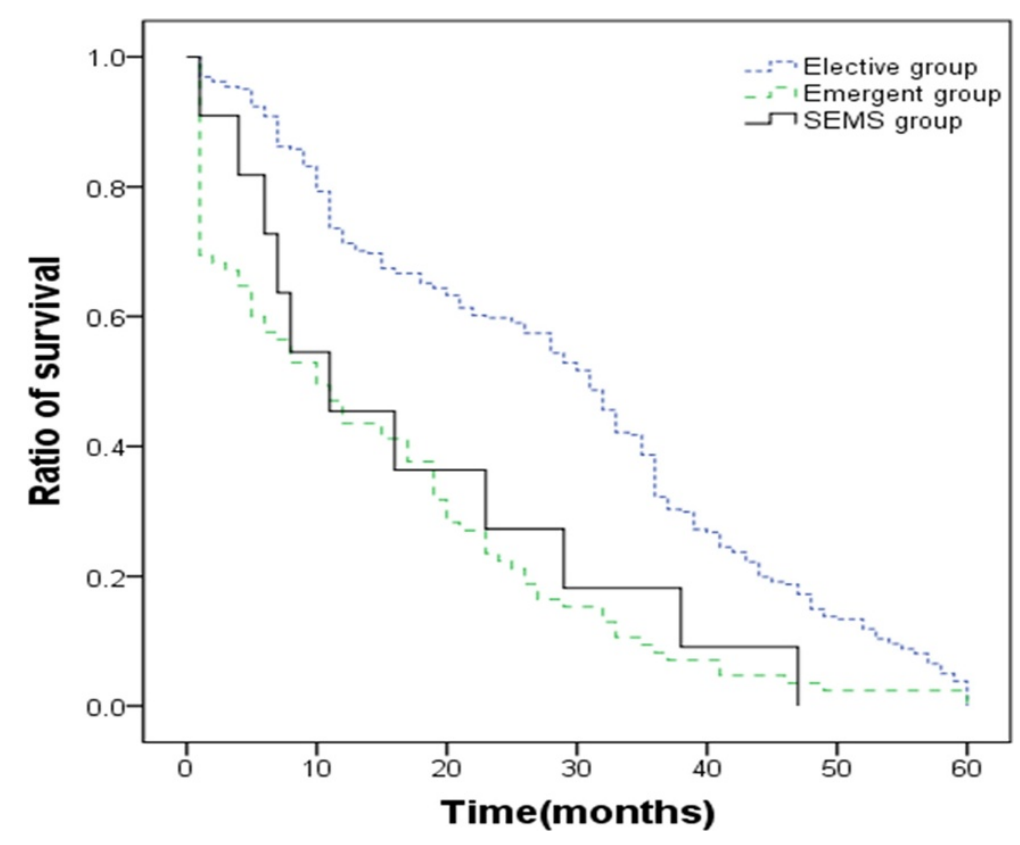

Figure 1 Kaplan-Meier curves of overall survival for octogenarian patients by procedures. SEMS, self-expanding metal stent.

2932 patients $\geq 80$ years old with CRC, Frank Marusch et al. showed $85 \%$ of these patients had a cardiovascular risk factor, and pulmonary comorbidity was found in $25.9 \%$ patients [7]. Our study revealed that the rate of having co-existing medical disease was $64.8 \%$ in the elective group and $84.8 \%$ in emergent group. Hypertension, COPD (chronic obstructive pulmonary diseases) and chronic heart disease were the major comorbidities. This led to high rate of ASA stage $\geq 3$ categories, with $42.9 \%$ in elective group and $59.8 \%$ in emergent group. Additional stress caused by the emergency and later tumor stage led to significantly higher of ASA score in octogenarian patients with emergent presentation.

As previous reports, the current study also revealed an age-related shift toward the colon in the distribution of $\mathrm{CRC}$, and up to $40 \%$ of cancers were located in the right colon $[8,9]$. Acute mechanical bowel obstruction, which was the most common complication and is a clinical indicator of locally advance disease, was more frequent in octogenarian patients. Glancarlo Basili et al. emergency surgery for CRC was carried out in $16 \%$ of elderly patients, compared with $4 \%$ in the younger group [10]. None of the patients in emergent group were firstly found by colonoscopy screening in our study. Colonoscopy should be recommended as method of choice in octogenarian patients if CRC is suspected. Although the literature concerning screening colonoscopy in the octogenarians is limited, several studies have suggested that a screening colonoscopy may improve poor outcomes by discovering CRC at an earlier stage [11,12].

As previous reports, for emergent surgery in the unprepared colon, RS is still one of the best operative alternatives in octogenarian patients [13-15]. In our research, a higher number of RPA (80.1\% vs $41.2 \%)$ and a lower number of RS ( $9.6 \%$ vs $30.6 \%$ ) were performed in the elective group compared to the emergent group. It is important to consider that the choice of procedure was not randomized, rather, RPA was only carried out when the surgeons believed that local and systemic conditions of the octogenarian patients were appropriate. The high rate of stoma might be attributed to hemodynamically unstable states and lower physiological reserves in the emergent group. RPA was used for 244 out of 346 patients in this study, and 11 (3.2\%) of these patients presented with anastomotic dehiscence. There were no differences in anastomotic dehiscence between the elective and emergent group. Compared to $3.0 \%$ and $6.3 \%$ reported in previous series' $[13,14]$, the anastomotic dehiscence rate was not higher in these octogenarian patients. RPA should be encouraged when the over-all physical condition of the patients is appropriate.

Surgery for CRC in octogenarian patients is associated with high morbidity and mortality. The risk of 
postoperative death rises to $11.9-38.0 \%$ after emergency surgery and $7.4-11.4 \%$ in elective cases [10], making the postoperative mortality rates of present study acceptable. Emergent management of CRC complications, such as obstructing and perforation, remains strongly associated with poorer outcomes in octogenarian patients. The reasons for this are to be seen in a reduced patient status and inadequate preoperative preparation. Ozturk and Yilmazlar reported in a multivariate logistic regression analysis that colorectal disease increased the risk of death by nine-fold in elderly patients undergoing surgery [16]. Emergency surgery, a well-known risk factor, increases operative mortality rates between three-fold- and 10-fold. This research confirm the results of previously published studies, in which morbidity rates of $25-81 \%$ and mortality rates of $17-30 \%$ have been reported [17-20]. Emergency status also caused a significant increase in length of stay and ICU admission.

Compared to elective group, patients had a lower survival; in emergent group, $43.5 \%$ versus $75.5 \%$ at 1 year and, $12.7 \%$ vs $46.4 \%$ at 3 years. This survival is also considerably lower than general population after colorectal surgery. These results may partly be explained by the fact that octogenarian patients, especially in emergent group, were more likely to present with a later stage of the disease, were less likely to receive curative surgery, and had higher postoperative mortality. Long-term survival figures could also be affected by the administration of adjuvant chemotherapy or radiotherapy and these treatments may be offered differently according to age. However, most octogenarian patients in this studies did not receive adjuvant treatment.

This retrospective study shows placement of SEMS to be an appealing option as a bridge to semi-elective surgery in octogenarian patients. Compared to emergent surgery, patients treated with SEMS had a significantly lower rate of complications. The mortality rate was $31.3 \%$ in the emergent group and $9.1 \%$ in patients received SEMS treatment. However, there was no significant difference. This factor may have reached significance if the study population was larger. Among patients who received SEMS, this study showed a marked reduction in stoma formation. SEMS provides a useful alternative to emergent surgical intervention in the management of acute colorectal obstruction for octogenarian patients [4].

The term 'getting old' may be defined as 'an inherent, progressive impairment of function with the passage of time, which cannot be averted, and which causes individuals to become more vulnerable to death' [21]. But However, it is difficult to define an age limit age that this occurs. As indicated in most previous studies regarding this definition, the physiological and chronic health status of the patient are much more important than the chronological age. Although advancing age is an independent risk factor for postoperative death in elderly patients undergoing colonic resection for cancer [22], in order to prevent high mortality, it should be emphasized that in octogenarians patients who require an operation for colorectal cancer, the operation should be performed as soon as conditions are optimized and should not be postponed. Age should not be a contraindication for surgery. A screening colonoscopy may improve poor outcomes in the octogenarian patients by discovering CRC at an earlier stage. Although emergency operations were associated with a poorer outcome, most patients in our study survived and left the hospital. When emergency of CRC occurs, identifying these high-risk patients and treating them promptly rather than delaying or denying surgery is the best option. SEMS may provide a useful alternative to emergent surgical intervention in the management of acute left-sided colorectal obstruction for octogenarian patients.

\section{Conclusions}

CRC is a predominant disease in elderly patients. Age should not be a contraindication for surgery. Octogenarians who undergo elective surgery have better results than those requiring emergent surgery, but both are quite acceptable and we recommend that surgical intervention should not be delayed.

\section{Abbreviations \\ ASA: American Society of Anesthesiologists; CRC: colorectal cancer; COPD: chronic obstructive pulmonary diseases; ICU: intensive care unit; RPA: resection and primary anastomosis; RS: resction and stoma; SEMS: self-expanding metal stents.}

\section{Competing interests}

The authors declare that they have no competing interests.

\section{Authors' contributions}

MGG: concept, design, data analysis, manuscript writing and editing. MGG, $J Z D, Z Y, Y W, Y B F, X Y H$ participated in the treatment of the patient.. All authors read and approved the version to be published.

\section{Acknowledgements}

We thank all patients, all doctors and nurses in our departments who enter this study.

Received: 6 April 2014 Accepted: 3 December 2014

Published: 17 December 2014

\section{References}

1. Stower MJ, Hardcastle JD: The results of 1115 patients with colorectal cancer treated over an 8-year period in a single hospital. Eur J Surg Oncol 1985, 11:119-123.

2. Colorectal Cancer Collaborative Group: Surgery for colorectal cancer in elderly patients: a systematic review. Lancet 2000, 356:968-974.

3. Shahir MA, Lemmens VE, van de Poll-Franse LV, Voogd AC, Martijn $H$, Janssen-Heijnen ML: Elderly patients with rectal cancer have a higher risk of treatment-related complications and a poorer prognosis than younger patients: a population-based study. Eur J Cancer 2006, 42:3015-3021.

4. Guo MG, Feng Y, Zheng Q, Di JZ, Wang Y, Fan YB, Huang XY: Comparison of self-expanding metal stents and urgent surgery for left-sided malignant colonic obstruction in elderly patients. Dig Dis Sci 2011, 56(9):2706-2710. 
5. Smith JJ, Lee J, Burke C, Contractor KB, Dawson PM: Major colorectal cancer resections should not be denied to the elderly. Eur I Surg Oncol 2002, 28:661-666.

6. Tan KY, Kawamura Y, Mizokami K, Sasaki J, Tsujinaka S, Maeda T, Konishi F: Colorectal surgery in octogenarian patients-outcomes and predictors of morbidity. Int J Colorectal Dis 2009, 24(2):185-189.

7. Marusch F, Koch A, Schmidt U, Steinert R, Ueberrueck T, Bittner R, Berg E, Engemann R, Gellert K, Arbogast R, Körner T, Köckerling F, Gastinger I, Lippert H, Working Group Colon/Rectum Cancer: The impact of the risk factor "age" on the early postoperative results of surgery for colorectal carcinoma and its significance for perioperative management. World $J$ Surg 2005, 29(8):1013-1021.

8. Arai T, Takubo K, Sawabe M, Esaki Y: Pathologic characteristics of colorectal cancer in the elderly: a retrospective study of 947 surgical cases. J Clin Gastroenterol 2000, 31:67-72.

9. Ikeda Y, Koyanagi N, Mori M, Ezaki T, Toyomasu T, Minagawa S, Tateishi H, Sugimachi K: Increased incidence of proximal colon cancer in the elderly. J Clin Gastoenterol 1996, 23:105-108.

10. Basili G, Lorenzetti L, Biondi G, Preziuso E, Angrisano C, Carnesecchi P, Roberto E, Goletti O: Colorectal cancer in the elderly. Is there a role for safe and curative surgery? ANZ J Surg 2008, 78(6):466-470.

11. Diggs JC, Xu F, Diaz M, Cooper GS, Koroukian SM: Failure to screen: predictors and burden of emergency colorectal cancer resection. Am J Manag Care 2007, 13:157-164.

12. Zerey M, Paton BL, Khan PD, Lincourt AE, Kercher KW, Greene FL, Heniford BT: Colonoscopy in the very elderly: a review of 157 cases. Surg Endosc 2007, 21:1806-1809.

13. Aslar AK, Ozdemir S, Mahmoudi H, Kuzu MA: Analysis of 230 cases of emergent surgery for obstructing colon cancer-lessons learned. J Gastrointest Surg 2011, 15(1):110-119.

14. Tan KK, Sim R: Surgery for obstructed colorectal malignancy in an Asian population: predictors of morbidity and comparison between left- and right-sided cancers. J Gastrointest Surg 2010, 14(2):295-302

15. Leong QM, Koh DC, Ho CK: Emergency Hartmann's procedure: morbidity, mortality and reversal rates among Asians. Tech Coloproctol 2008, 12(1):21-25.

16. Ozturk $E$, Yilmazlar T: Factors affecting the mortality risk in elderly patients undergoing surgery. ANZ J Surg 2007, 77:156-159.

17. Modini C, Romagnoli F, De Milito R, Romeo V, Petroni R, La Torre F, Catani M: Octogenarians: an increasing challenge for acute care and colorectal surgeons. An outcomes analysis of emergency colorectal surgery in the elderly. Colorectal Dis 2012, 14(6):e312-e318.

18. Pavlidis TE, Marakis G, Ballas K, Rafailidis S, Psarras K, Pissas D, Papanicolaou K, Sakantamis A: Safety of bowel resection for colorectal surgical emergency in the elderly. Colorectal Dis 2006, 8:657-662.

19. McGillicuddy EA, Schuster KM, Davis KA, Longo WE: Factors predicting morbidity and mortality in emergency colorectal procedures in elderly patients. Arch Surg 2009, 144:1157-1162.

20. Leong QM, Aung MO, Ho CK, Sim R: Emergency colorectal resections in Asian octogenarians: factors impacting surgical outcome. Surg Today 2009, 39:575-579.

21. Richardson JD, Cocanour CS, Kern JA, Garrison RN, Kirton OC, Cofer JB, Spain DA, Thomason MH: Perioperative risk assessment in elderly and high-risk patients. J Am Coll Surg 2004, 199:133-146.

22. Faiz O, Haji A, Bottle A, Clark SK, Darzi AW, Aylin P: Elective colonic surgery for cancer in the elderly: an investigation into postoperative mortality in English NHS hospitals between 1996 and 2007. Colorectal Dis 2011. 13(7):779-785

doi:10.1186/1477-7819-12-386

Cite this article as: Ming-gao et al.: Colorectal cancer treatment in octogenarians: elective or emergency surgery? World Journal of Surgical Oncology 2014 12:386.

\section{Submit your next manuscript to BioMed Central and take full advantage of:}

- Convenient online submission

- Thorough peer review

- No space constraints or color figure charges

- Immediate publication on acceptance

- Inclusion in PubMed, CAS, Scopus and Google Scholar

- Research which is freely available for redistribution

Submit your manuscript at www.biomedcentral.com/submit
C Biomed Central 